\title{
Un kilo y medio más...
}

\author{
A kilo and a half more...
}

Se presenta el caso de una mujer de 25 años, con obesidad grado II, sin antecedentes patológicos relevantes y sin historia de traumatismo importante reciente. La paciente recurrió al Servicio de Urgencias por cuadro de dolor lumbar izquierdo con irradiación abdominal de moderada intensidad que empeora con los movimientos y a la palpación, con un año de evolución pero con períodos asintomáticos, y con empeoramiento significativo en los últimos dos días.

En la exploración física, a la palpación abdominal, destacó dolor leve en el flanco superior izquierdo, puño percusión lumbar izquierda negativa. En la analítica, no había alteraciones en el hemograma, bioquímica y coagulación.

La Ecografía Abdominal y posteriormente la Resonancia magnética mostraron: voluminosa formación quística intraesplénica que comprimía el cuerpo y la cola del páncreas y desviaba el estómago; extensión cráneo-caudal $15 \mathrm{~cm}$, laterolateral $11 \mathrm{~cm}$ y antero-posterior $12 \mathrm{~cm}$. La paciente se sometió a una esplenectomía. La pieza obtenida pesaba 1498g, y estaba constituida por tejido esplénico sin revestimiento epitelial reconocible, y una cavidad con material líquido, con pared con áreas calcificadas - pseudoquiste esplénico. El quiste esplénico es una entidad rara, con menos de 1000 casos descritos. Se clasifican, según Martin, en tipo I (primarios o verdaderos) y tipo II (secundarios o pseudoquistes). Los quistes tipo I poseen cápsula epitelial, y pueden ser de naturaleza parasitaria 0 no parasitaria, pudiendo ser aún de causa congénita, vascular 0 neoplásica. Los quistes tipo II corresponden al $75 \%$ de los quistes, no tienen revestimiento epitelial y son secundarios a trauma, infeción o infarto; la mayoría son asintomáticos. Microscópicamente, los pseudoquistes se componen de tejido fibroso denso, a menudo calcificado, sin epitelio de revestimiento; pueden contener una mezcla de sangre y restos necróticos en su interior.

Las pruebas de imagen son útiles en la identificación del quiste y posibles complicaciones, pero no ayudan en la distinción del tipo de quiste, teniendo la anatomía patológica un papel fundamental en el diagnóstico final.

El tratamiento quirúrgico está recomendado en os quistes esplénicos con un diámetro superior a 4-5 cm, debido al riesgo de complicaciones. La laparotomía con esplenectomía ha sido el método de elección preferencial para el tratamiento.

\section{Bibliografía}

1. Albuquerque J, Mónica A, Germano A, Tavares A. Quisto epidermoide esplénico - aspectos imagiológicos. Acta Médica Portuguesa. 2005; 18: 227-230.

2. Galyfos G, Touloumis Z, Palogos K, Stergios K, Chalasti M, Lavant L, et al. Oversized pseudocysts of the spleen: Report of two cases Optimal management of oversized pseudocysts of the spleen. International Journal of Surgery Case Reports. 2014; 5: 104-107.

3. Lobascio P, Carbotta G, Laforgia R, Fedelle S, Sederino MG, Minafra M, et al. Total laparoscopic splenectomy for giant epidermoid cyst: a case report. Giornale di Chirurgia. 2017; 38 (4): 202-204.
Imagen 1. Pseudoquiste esplénico con extensión cráneo-caudal $15 \mathrm{~cm}$, laterolateral $11 \mathrm{~cm}$ y antero-posterior $12 \mathrm{~cm}$. A - corte longitudinal. B - corte axial.
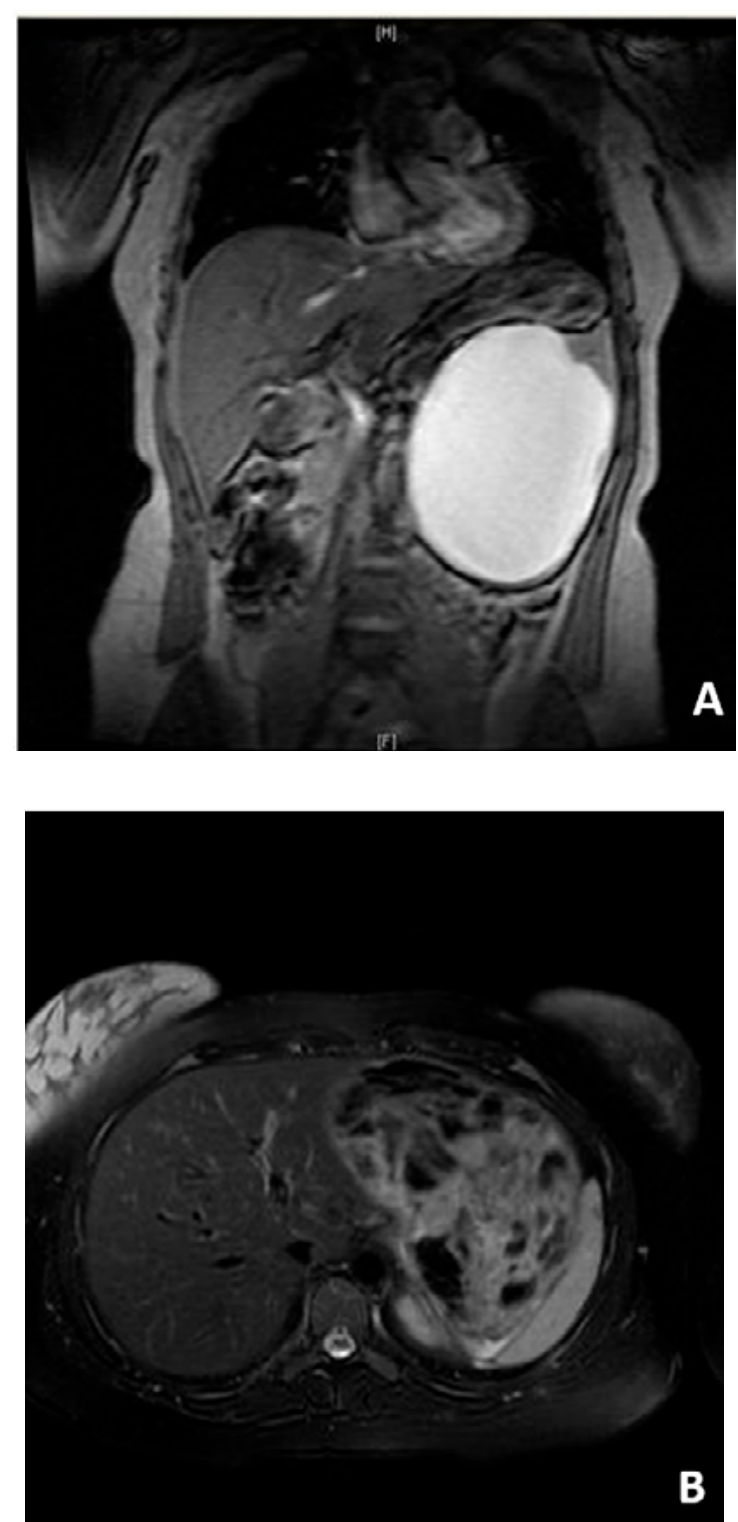

Diagnóstico

\section{Quiste esplénico}

\section{Susana Travassos Cunha, Juliana Silva \\ Centro Hospitalar de Leiria}

Correspondencia: susanam.t.cunha@gmail.com

Cómo citar este artículo: Travassos Cunha S, Silva J

Un kilo y medio más.... Galicia Clin 2019; 80 (3): 62

Recibido: 24/08/2018; Aceptado: 10/09/2018 // http://doi.org/10.22546/53/1753 